\title{
Article \\ Plasmon-Enhanced Antibacterial Activity of Chiral Gold Nanoparticles and In Vivo Therapeutic Effect
}

\author{
Yuelong $\mathrm{Xu}^{\dagger}{ }^{\dagger}$, Hongxia Wang ${ }^{\dagger}$, Min Zhang, Jianhao Zhang and Wenjing Yan *(D) \\ National Center of Meat Quality and Safety Control, College of Food Science and Technology, \\ Nanjing Agricultural University, Nanjing 210095, China; 2019108056@njau.edu.cn (Y.X.); \\ whxia1010@163.com (H.W.); 17854338808@163.com (M.Z.); nau_zjh@njau.edu.cn (J.Z.) \\ * Correspondence: ywj1103@njau.edu.cn; Tel.: +86-158-9589-3834 \\ + These authors contributed equally to this work.
}

Citation: Xu, Y.; Wang, H.; Zhang, M.; Zhang, J.; Yan, W.

Plasmon-Enhanced Antibacterial Activity of Chiral Gold Nanoparticles and In Vivo Therapeutic Effect. Nanomaterials 2021, 11, 1621. https:// doi.org/10.3390/nano11061621

Academic Editors: Krasimir Vasilev and Ana María Díez-Pascual

Received: 23 May 2021

Accepted: 15 June 2021

Published: 21 June 2021

Publisher's Note: MDPI stays neutral with regard to jurisdictional claims in published maps and institutional affiliations.

Copyright: (c) 2021 by the authors. Licensee MDPI, Basel, Switzerland. This article is an open access article distributed under the terms and conditions of the Creative Commons Attribution (CC BY) license (https:// creativecommons.org/licenses/by/ $4.0 /)$.

\begin{abstract}
D-cysteine (D-cys) has been demonstrated to possess an extraordinary antibacterial activity because of its unique steric configuration. However, inefficient antibacterial properties seriously hinder its wide applications. Here, cysteine-functionalized gold nanoparticles (D-/L-Au NPs) were prepared by loading D-/L-cysteine on the surface of gold nanoparticles for the effective inhibition of Escherichia coli (E. coli) in vitro and in vivo, and the effects on the intestinal microflora in mice were explored during the treatment of $E$. coli infection in the gut. We found that the antibacterial activity of D-/L-Au NPs was more than 2-3 times higher than pure D-cysteine, L-cysteine and Au NPs. Compared with L-Au NPs, D-Au NPs showed the stronger antibacterial activity, which was related to its unique steric configuration. Chiral Au NPs showed stronger destructive effects on cell membrane compared to other groups, which further leads to the leakage of the cytoplasm and bacterial cell death. The in vivo antibacterial experiment illustrated that D-Au NPs displayed impressive antibacterial activity in the treatment of E. coli-infected mice comparable to kanamycin, whereas they could not affect the balance of intestinal microflora. This work is of great significance in the development of an effective chiral antibacterial agent.
\end{abstract}

Keywords: gold nanoparticles; chiral; D-cysteine; antibacterial activity; in vivo

\section{Introduction}

Food safety is the main problem caused by foodborne pathogens, including Escherichia coli (E. coli), Salmonella and Staphylococcus aureus (S. aureus), etc. [1-3], which is the most concerning issue in public health [1-3]. E. coli, a Gram-negative, non-sporulating facultative anaerobe bacteria, is commonly found in the lower intestine and known as a harmless commensal of the gastrointestinal tract in warm-blooded animals [4-6]. However, E. coli can produce an enzyme called broad-spectrum $\beta$-lactamase that cause urinary tract infections. Furthermore, urinary tract infections may lead to some serious diseases that span from the gastrointestinal tract to extraintestinal sites such as the blood stream and central nervous system, which can be life-threatening $[7,8]$. Antibiotic treatment is currently the most effective method, but it is easy to promote the emergence of multi-drug resistant E. coli, which constitutes one of the dominant challenges to human health [9-11]. Additionally, the obvious and continuous decrease in the number of approved antibiotics in the past 10 years has exacerbated the increasingly threatening circumstances [12,13]. This situation has created an urgent need to discover novel antibacterials and treatment strategies [14].

Inorganic nano antibacterial agents have become a research hotspot in recent years due to their good heat resistance, broad-spectrum antibacterial properties and no drug resistance [15-19]. Among them, silver nanoparticles (Ag NPs) were once thought to be the most promising alternative to antibiotics and were widely used in many different fields [20,21]. However, they have been shown to have obvious cytotoxicity and genotoxicity (i.e., low 
selectivity) against healthy mammalian cells, which severely limits their practical application [22]. Other inorganic nanomaterials, for example, titanium dioxide $\left(\mathrm{TiO}_{2}\right) \mathrm{NPs}$ and graphene oxide (GO), cause cytotoxicity against normal mammalian cells because of the excess reactive oxygen species (ROS) [23]. Thus, developing new nanomaterials with targeted antibacterial activity against bacteria represents a great challenge.

Gold nanoparticles (Au NPs) have received more attention due to their excellent biocompatibility, stability and low cytotoxicity [24-28]. However, the antibacterial activity of Au NPs cannot adequately meet the needs of practical applications compared with Ag NPs and $\mathrm{TiO}_{2} \mathrm{NPs}$ [29-31]. It has been demonstrated that a modification of the surface with an antibiotic can effectively enhance the antibacterial activity of gold nanoparticles [32], whereas the process often requires exogenous antimicrobial laser irradiation and still might not be able to avoid the emergence of drug resistance. Fortunately, the high binding affinity of gold atoms facilitates the conjugation of other functional ligands onto the surface of $\mathrm{Au}$ NPs, such as specific proteins and amino acids $[33,34]$, which provides the possibility for gold nanoparticles to be exploited as antibacterial agents without existing antibiotics [35].

D-cysteine (D-cys), an enantiomer of natural L-cysteine (L-cys), has been proved to significantly inhibit the growth of Gram negative E. coli by inhibiting the activity of threonine deaminase, which may further affect the synthesis of isoleucine, leucine and valine in bacteria [36-38]. In spite of this, D-cys is not widely used in practical applications because of its inefficient antibacterial properties. Here, functional gold nanomaterials (D-/L$\mathrm{Au}$ NPs) with stable antibacterial effects were synthesized using cysteine as a ligand. The structural characterization of new materials and the antibacterial activity against $E$. coli were investigated in vitro. To investigate the antibacterial mechanism of D-/L-Au NPs against E. coli, confocal laser scanning microscopy (CLSM), scanning electron microscopy (SEM) and transmission electron microscopy (TEM) were performed. Moreover, the therapeutic effect of D-Au NPs on intestinally infected mice and the influence on intestinal flora were investigated, compared with kanamycin, which further demonstrates the prominent bactericidal application potential. The work we mentioned above has never been reported before, and it has important theoretical significance for the development of a new chiral antibacterial agent.

\section{Materials and Methods}

\subsection{Materials}

D-cysteine, L-cysteine, sodium citrate, gold tetrachloroaurate trihydrate (HAuCl4), kanamycin and sodium hydroxide were purchased from Sigma-Aldrich (Shanghai, China). Broth edium and eosin-methylene blue agar (EMB) were purchased from Hope Biotechnology Ltd. (Qingdao, China). LIVE/DEAD ${ }^{\circledR}$ BacLightTM Bacterial Visibility Kit was purchased from Invitrogen. Escherichia coli (E. coli) was obtained from Guangdong Huankai Microbiology technology co. Ltd. Guangdong province, China)

\subsection{Synthesis of Chiral Cysteine Functionalized Gold Nanoparticles}

Chiral cysteine functionalized gold nanoparticles (D-/L-Au NPs) were prepared by the following method: first, $2.5 \mathrm{~mL}$ of $12 \mathrm{mM} \mathrm{HAuCl}_{4}$ was brought to boil in $50 \mathrm{~mL}$ of distilled water. Then, $1.0 \mathrm{~mL}$ of $1 \%$ trisodium citrate was quickly added to the sample under high-speed stirring. The solution was kept for $20 \mathrm{~min}$ until the color turned wine red. Finally, $1.0 \mathrm{~mL}$ of $0.6 \% \mathrm{NaOH}$ and $1.0 \mathrm{~mL}$ of $1.8 \%$ cysteine was in turn added to the solution under vigorous stirring for $2 \mathrm{~h}$. The solution was centrifuged at 11,000 rpm for $20 \mathrm{~min}$, and the precipitate was re-suspended in $10 \mathrm{~mL}$ distilled water to obtain experimental materials.

\subsection{Bacterial Culture}

E. coli (ATCC25922) were cultured in LB medium at $37^{\circ} \mathrm{C}$ for $12 \mathrm{~h}$ under shaking at $200 \mathrm{rpm}$. The bacterial suspension was centrifuged at $6000 \mathrm{rpm}$ for $10 \mathrm{~min}$ at $4{ }^{\circ} \mathrm{C}$ and re-suspended in sterile saline solution $(0.9 \% \mathrm{NaCl})$. The concentration of $E$. coli cells was quantified to $10^{7}$ colony-forming units per millimeter (CFU/mL) by $\mathrm{OD}_{600}$ measurements. 


\subsection{Antibacterial Activity Assays}

To measure the dynamic bacteriostatic properties of D-/L-Au NPs on E. coli, $1 \mathrm{~mL}$ of $10^{7} \mathrm{CFU} / \mathrm{mL}$ E. coli suspension was mixed with $1 \mathrm{~mL}$ of $3 \mathrm{mg} / \mathrm{mL}$ D-Au NPs or L-Au NPs solution, respectively; the samples were cultured at $37^{\circ} \mathrm{C}$ for $24 \mathrm{~h}$. The aseptic saline group was used as negative control; Au NPs, L-cys and D-cys with the same content were used as positive control, respectively. The bacterial growth was evaluated every $1 \mathrm{~h}$ by recording the optical density at $600 \mathrm{~nm}\left(\mathrm{OD}_{600} \mathrm{~nm}\right)[39,40]$.

The antibacterial activity of D-/L-Au NPs $(3 \mathrm{mg} / \mathrm{mL})$ against E. coli $\left(10^{7} \mathrm{CFU} / \mathrm{mL}\right)$ after $6 \mathrm{~h}$ was determined by plate counting method. The mixture of D-/L-Au NPs solution and E. coli suspension was collected and the 10-fold serially diluted cells were spotted onto Violet Red Bile Agar (VRBA). The CFUs were counted after overnight incubation at $37^{\circ} \mathrm{C}$. The percentage of dead bacteria was calculated according to the previous article [41].

\subsection{Live/Dead Bacterial Assay}

Confocal laser scanning microscopy (CLS) was performed to characterize the destruction of D-/L-Au NPs on the cell membrane of E. coli. D-/L-Au NPs were incubated with

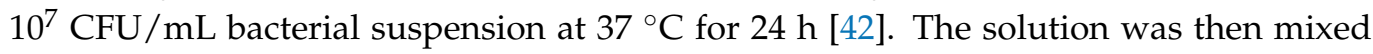
with dye solution containing SYTO9 and propidium iodide (PI) for $20 \mathrm{~min}$ at room temperature. The stained sample was observed under a confocal laser scanning microscope (TCS-SP2, Leica, Weztlar, Germany). PI fluorescent dye can only bind to the DNA in the cell membrane of incomplete bacteria, emitting red fluorescence. The SYTO9 fluorescent dye can bind to DNA in the cell membrane of intact bacteria, producing green fluorescence. The effect of D-/L-Au NPs on the cell membrane of E. coli was evaluated by the ratio of red/green fluorescence, which can be used to indicate the ratio of live and dead bacteria.

\subsection{In Vivo Antibacterial Activity in Infected Mice}

The animals were maintained in the Center for Experimental Animals at Nanjing Agricultural University (permit number: SYXK (SU) 2017-0007), following the protocols approved by the Ethical Committee of Nanjing Agricultural University, China. Twenty female BALB/c mice (6-8 weeks, 18-22 g) were purchased from the Center of Comparative Medicine Centre of Yangzhou University (permit number: SCXK (SU) 2012-0004) and allowed to acclimatize for 3 days in the laboratory. A bacteria-infected mouse model was created by oral gavage with $200 \mu \mathrm{L}$ of $E$. coli containing $1 \times 10^{7} \mathrm{CFU} / \mathrm{mL}$ into female BALB/c mice $(n=15)$ [43]. The healthy mice $(n=5)$, as a group, were not infected with E. coli. One day postinfection with $E$. coli, mice were randomly divided into three groups $(\mathrm{n}=5)$ and treated with $200 \mu \mathrm{L}$ PBS, kanamycin $\left(2.5 \mathrm{mg} \mathrm{kg}^{-1}\right)$ and D-Au NPs $\left(2.5 \mathrm{mg} \mathrm{kg}^{-1}\right)$, respectively, twice in one day with a $12 \mathrm{~h}$ interval. The activity and body weight of mice were recorded throughout the entire treatment period. After three days, all mice were sacrificed and the intestinal tissues (colon, cecum and small intestinal) were isolated, which were then placed in sterile PBS. Aliquots of diluted homogenized intestinal tissues were plated on agar, on which the grown colonies were counted for analysis [44]. The number of E. coli in the intestinal tissues of mice was evaluated by the LB-agar plate dilution method.

\subsection{Changes of Intestinal Microflora in Mice}

To explore the effect of D-cysteine-functionalized Au NPs on the changes of intestinal microflora in mice, fecal genomic DNA of mice was extracted by QiAamp DNA stool MiniKit (NO.51504, Qiagen, Venlo, Germany) [45,46]. Total DNA was quantified using a NanoDrop $2000^{\circledR}$ spectrophotometer (Thermo Fisher Scientific, Massachusetts, USA). The resulting DNA was amplified with barcoded specific bacterial primers targeting the $16 \mathrm{~S}$ rRNA gene V3 and V4 region using primers with the Primer F (Illumina adapter sequence 1+CCTACGGGNGGCWGCAG) and Primer R (Illumina adapter sequence 2+GACTACHVGGGTATCTAATCC). The Library quality was determined using an Agilent 2100 Bioanalyzer (Agilent Technologies, California, USA). A unit of 250 bps paired-end sequencing of the amplicon was performed using MiSeq Reagent Kit v3 (Illumina, California, 
USA). After splicing, quality control and filtering the Barcode sequence, the high-quality clean reads were obtained for OTUs cluster analysis. The OTU representation sequence was compared with the Geen Gene database. According to the clustering results, Alpha and Beta diversity analyses were performed. The kinds and abundance of the intestinal microflora were analyzed at the level of phylum and family.

\section{Results and Discussion}

\subsection{Characterization}

Transmission electron microscopy (TEM) was used to characterize the morphology of chiral Au NPs. As showed in the Figure 1A insert, chiral Au NPs were well-dispersed with the diameter of $15 \pm 2 \mathrm{~nm}$, which was not significantly different from spherical Au NPs. The UV-VIS spectrum of D-/L-Au NPs compared with Au NPs in the absorption maximum shifts from 520 to $522 \mathrm{~nm}$ (Figure 1A). Circular dichroism (CD) was used to determine the stereo configuration of chiral Au NPs [47]. As shown in Figure 1B, L-Au NPs and D-Au NPs had an opposite characteristic peak in the wavelength range of $20-250 \mathrm{~nm}$, which were consistent with L-cysteine and D-cysteine, respectively. As pure Au NPs showed no characteristic peaks in the ultraviolet region, it can be indicated that L-/D-cysteine were successfully modified on the surface of Au NPs (Figure 1B). To explore the effect of chiral cysteine on the surface of gold nanoparticles, the dynamic light scattering (DLS) and Zeta potential were measured. DLS results showed that the mean hydrodynamic sizes of Au NPs, L-Au NPs and D-Au NPs were 32.67, 50.75 and $62.06 \mathrm{~nm}$, respectively. The diameters of NPs were slightly larger than the size obtained in TEM images, which may be related to the hydration of chiral Au NPs by the surrounding water (Figure 1C) [48]. The Zeta potential values of Au NPs, L-Au NPs and D-Au NPs were $-35.5 \pm 1.1,-33.8 \pm 0.9$ and $-29.0 \pm 1.2 \mathrm{mV}$, respectively, demonstrating that the coupling of $\mathrm{SH}$ can reduce the negative charge on the surface of Au NPs (Figure 1D).
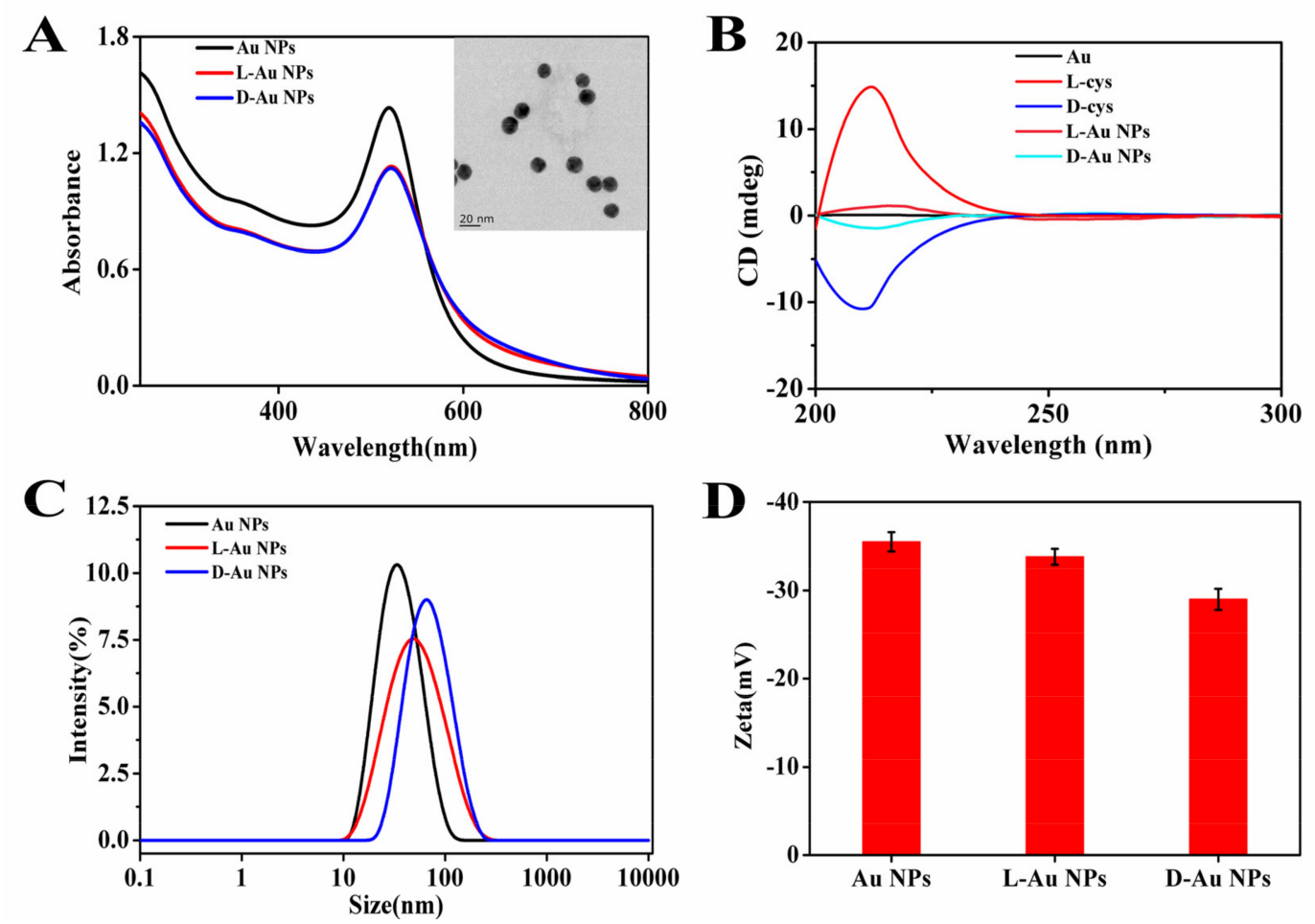

Figure 1. Characterizations of cysteine-functionalized gold nanoparticles(D-/L-Au NPs). (A) Absorption spectrum of $\mathrm{Au}$ NPs, L-Au NPs and D-Au NPs (Insert: TEM image of D-Au NPs). (B) Circular dichroic spectrum, (C) particle size distribution and (D) zeta potential of Au NPs and chiral Au NPs. (Dates are presented as the mean \pm s.d.). 


\subsection{In Vitro Antibacterial Activities of Chiral Au NPs}

To evaluate the antibacterial activity of D-/L-Au NPs, E. coli as a typical Gram-negative bacteria was used in the test. Agar plate images and quantitative histograms of dead bacterial are shown in Figure 2A. It can be seen that cysteine-functionalized Au NPs displayed remarkable bactericidal properties against E. coli compared with free D-/Lcysteine or pure Au NPs at the same dosage. The lethality rate of D-Au NPs and L-Au NPs toward E. coli were increased to $96.8 \%$ and $65.4 \%$, respectively, while the lethality rate of D-cys, L-cys or Au NPs was only $46 \%, 27 \%$ and $20 \%$, respectively. The significant antibacterial activity of D-/L-Au NPs was attributed to two aspects: first, the stability of cysteine is greatly increased after immobilization via Au-S bonding on the surface of $\mathrm{Au}$ NPs, which has a significant association with antimicrobial properties [49]. Besides, $\mathrm{Au}$ NPs may concentrate antibacterial cysteine on their surfaces to result in polyvalent effects; thus, D-/L-Au NPs can specifically attack biological targets in bacteria [50,51]. We also noticed that D-Au NPs displayed higher antibacterial activity than L-Au NPs, which may be related to their unique stereo configuration. D-amino acids have been shown to play an important role in the regulation of bacterial physiological structure and function [52].

A

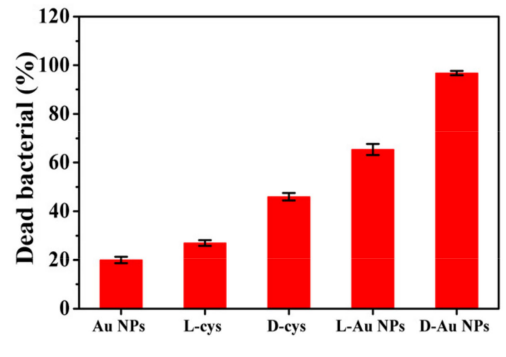

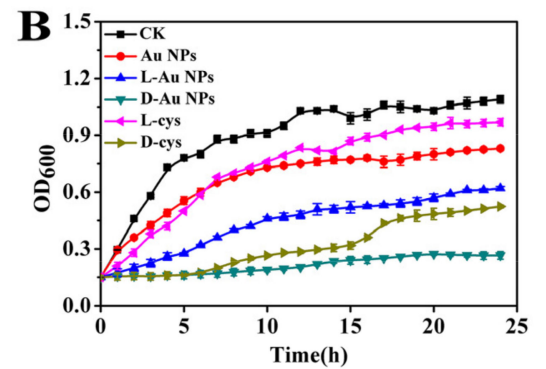

L-Au NPs

D-Au NPs

Au NPs
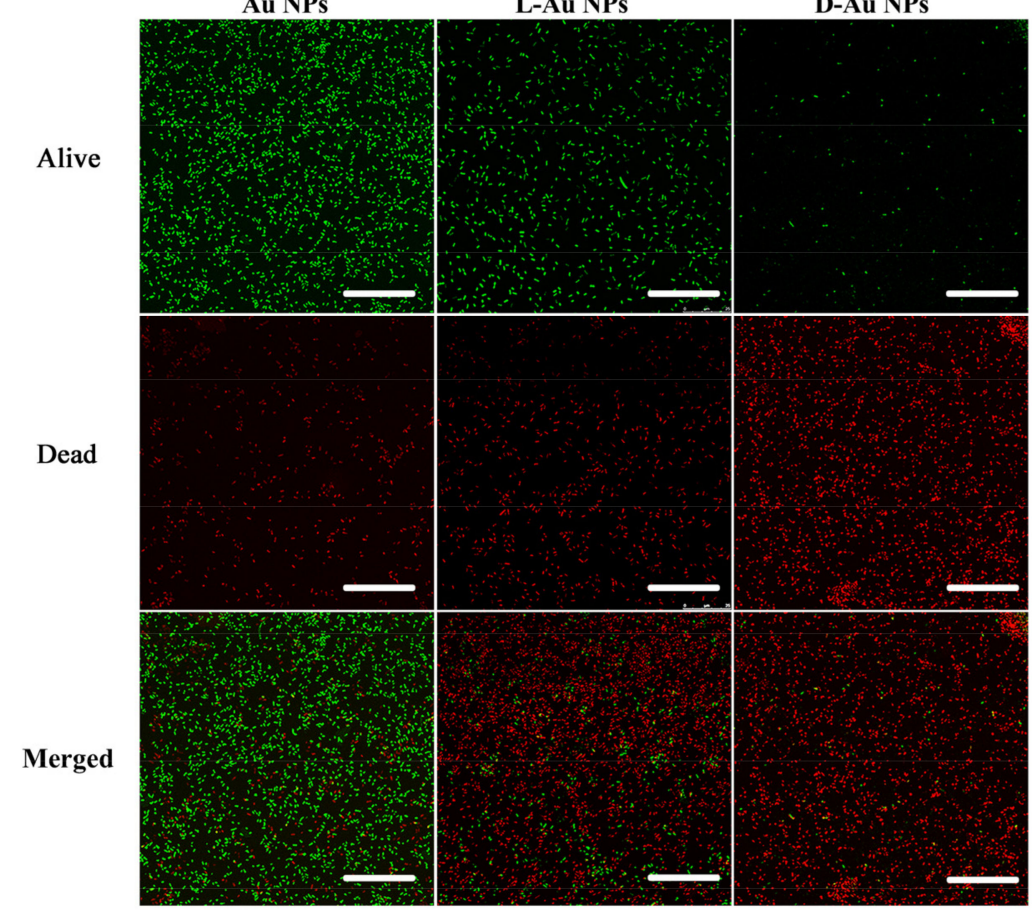

C

Figure 2. (A) Percentage of dead E. coli after treatment with D-/L-cysteine, Au NPs and D-/L-Au NPs at $3 \mathrm{mg} / \mathrm{mL}$ for $12 \mathrm{~h}$, respectively. Insert: Agar plates showing bacterial colonies after different treatments (Dates are presented as the mean \pm s.d.). (B) The growth kinetics of $E$. coli incubated with D - / L -cysteine, Au NPs and D-/L-Au NPs for 24 h, respectively. (C) Confocal microscopy images of E. coli after treatment with Au NPs, L-Au NPs and D-Au NPs, for $12 \mathrm{~h}$, respectively. The scale bar is $25 \mu \mathrm{m}$. 
To further demonstrate the antibacterial property of chiral Au NPs, the growth curve of E. coli cells after treatment was measured at OD $600 \mathrm{~nm}$ within $24 \mathrm{~h}$. As shown in Figure 2B, E. coli treated with Au NPs and L-cys showed a delayed exponential growth compared with the control group (CK), but the OD value increased rapidly after $4 \mathrm{~h}$. The D-cys and L-Au NPs solutions were discovered to moderately inhibit bacterial growth and showed better antimicrobial activity than the pure L-cys and Au NPs. In contrast, a slight increase was observed in the OD value for bacteria treated with D-Au NPs within $24 \mathrm{~h}$, showing the strongest and long-term bactericidal activity as opposed to the other samples [53]. Moreover, in vitro antibacterial activity of D-Au NPs was evaluated using the Live/Dead bacterial viability assay, which can be used to distinguish between live cells with intact membranes and dead cells with damage membranes. As shown in Figure 2C, almost all E. coli treated with D-Au NPs displayed red fluorescence; this means that most bacteria after treatment were dead and the red fluorescence intensity was stronger compared with $\mathrm{Au}$ NPs or L-Au NPs, indicating that D-Au NPs exhibited high antibacterial activity against $E$. coli. The result is consistent with that determined by the plate count method.

\subsection{Antibacterial Mechanism of D-/L-Au NPS}

To gain insight into the antimicrobial mechanism of D-/L-Au NPs, $3 \mathrm{mg} / \mathrm{mL}$ of nanomaterials were incubated with $10^{7} \mathrm{CFU} / \mathrm{mL}$ of $E$. coli for $12 \mathrm{~h}$; the morphology changes of bacteria were then investigated by transmission electron microscope (TEM) and scanning electron microscope (SEM). As shown in Figure 3A, compared with Au NPs or L-Au NPs, D-Au NPs seriously damaged the cell membrane of E. coli, led to cytoplasm leakage and cell death. The results can also be proved by SEM images. It is clear that compared with Au NPs and L-Au NPs, E. coli displayed more severe changes in morphology in the presence of the D-Au NPs; the wrinkled cell wall and the disappeared cellular integrity may reflect leakage of cytoplasmic content outside the bacterial cell (Figure 3B). This is the leaked cytoplasm (proteins and DNA) from bacteria adhered to the surface of D-Au NPs, resulting in the formation of some tiny particles outside the cell membrane [54].

The severe disruption of D-Au NPs was attributed to the inherent antibacterial property of D-cys and the synergistic effects of Au NPs [41]. We noticed that nanoparticles were mainly adsorbed on the cell membrane or aggregated outside the cell, which may be related to the long treatment time. According to the previous report, engineered nanomaterials enter cells via several pathways, including nonspecific endocytosis, physical electroporation or targeted uptake based on the surface functionalization [55]. As for the antibacterial mechanism of D-Au NPs, we hypothesis that D-cys-modified Au NPs may specifically bind to the proteins on the cell membrane of bacteria and result in the destruction of cell membrane integrity by changing the structure of proteins [56], which was consistent with the TEM images (Figure 3A). Chiral nanomaterials-induced structure changes of proteins have been reported in previous works $[57,58]$. On the other hand, a portion of D-Au NPs may enter the bacteria by endocytosis, affecting the physiological activity of bacteria through interactions with proteins and DNA, resulting in cell death. Gong et al. reported that D-glutamic acid modified graphene quantum dot (GQD) can specifically bind to cytoplasmic MurD and inhibit its catalyzing activity, which was directly related to the biosynthesis of intracellular peptidoglycan and the damage of cell wall [59]. It has been reported that D-cys can inhibit the catalyzing activity of threonine deaminase in E. coli and further affect the synthesis of essential amino acids in bacteria. The antibacterial mechanism of D-Au NPs at the molecular level will be systematically investigated through future research. 


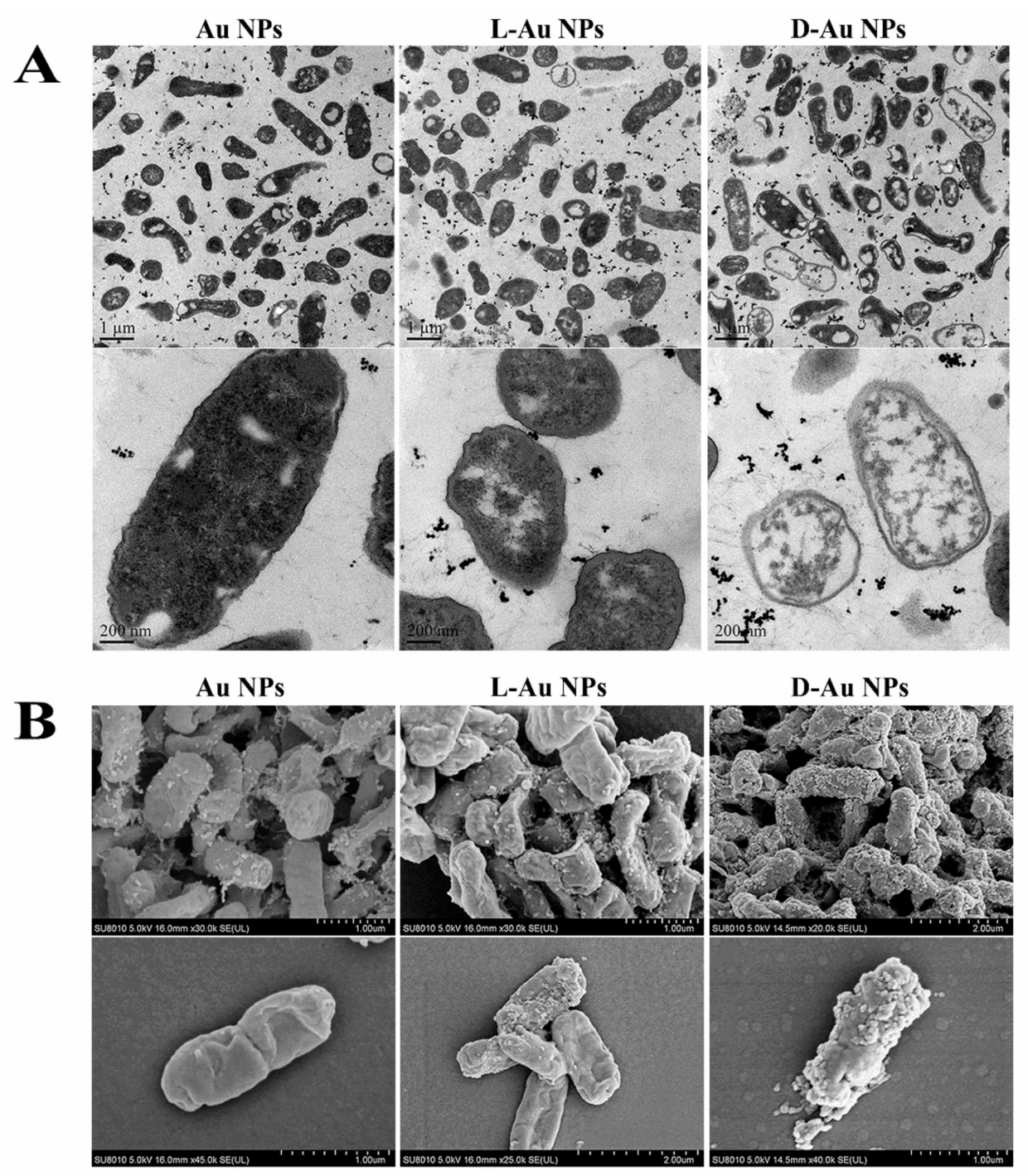

Figure 3. (A) TEM and (B) SEM images (5.0 kV for work) of E. coli after treatment with Au NPs, L-Au NPs and D-Au NPs for $12 \mathrm{~h}$, respectively.

\subsection{In Vivo Therapy of Mice Suffering from E. coli Infection}

To assess antibacterial efficacy in a complex physiological environment, the mice suffering from $E$. coli infection in the intestine were treated with D-Au NPs (Figure 4A). The healthy group was not infected with E. coli. Mice infected with E. coli in the model group were treated with PBS. The positive control was treated with kanamycin, which was used for clinical therapy for most Gram-negative bacteria infections. Changes in body weight in mice during treatment are important indicators to assess therapeutic efficacy. As shown in Figure $4 \mathrm{~B}$, the body weight of mice treated with D-Au NPs showed a slight decrease on the first day and began to slowly recover and increasee at 2 days postinfection; in contrast, the body weight of mice treated with kanamycin recovered after 4 days postinfection, and the body weight of mice treated with PBS did not significantly increase. Figure $4 \mathrm{C}$ shows the bacterial CFU in the colon, cecum and small intestine in mice after treatment. The results indicated that treatment with D-Au NPs on E. coli infected mice resulted in similar kanamycin effects. Specifically, after treatment with D-Au NPs, the E. coli count in small-intestine samples was lower by more than 1.5 orders of magnitude compared to the PBS-treated groups, similar to the kanamycin group, and the bacterial concentrations in the colon and cecum in mice were down to the level close to the healthy group (Figure 4D). D-Au NPs are effective in the treatment of E. coli infection in mice. 


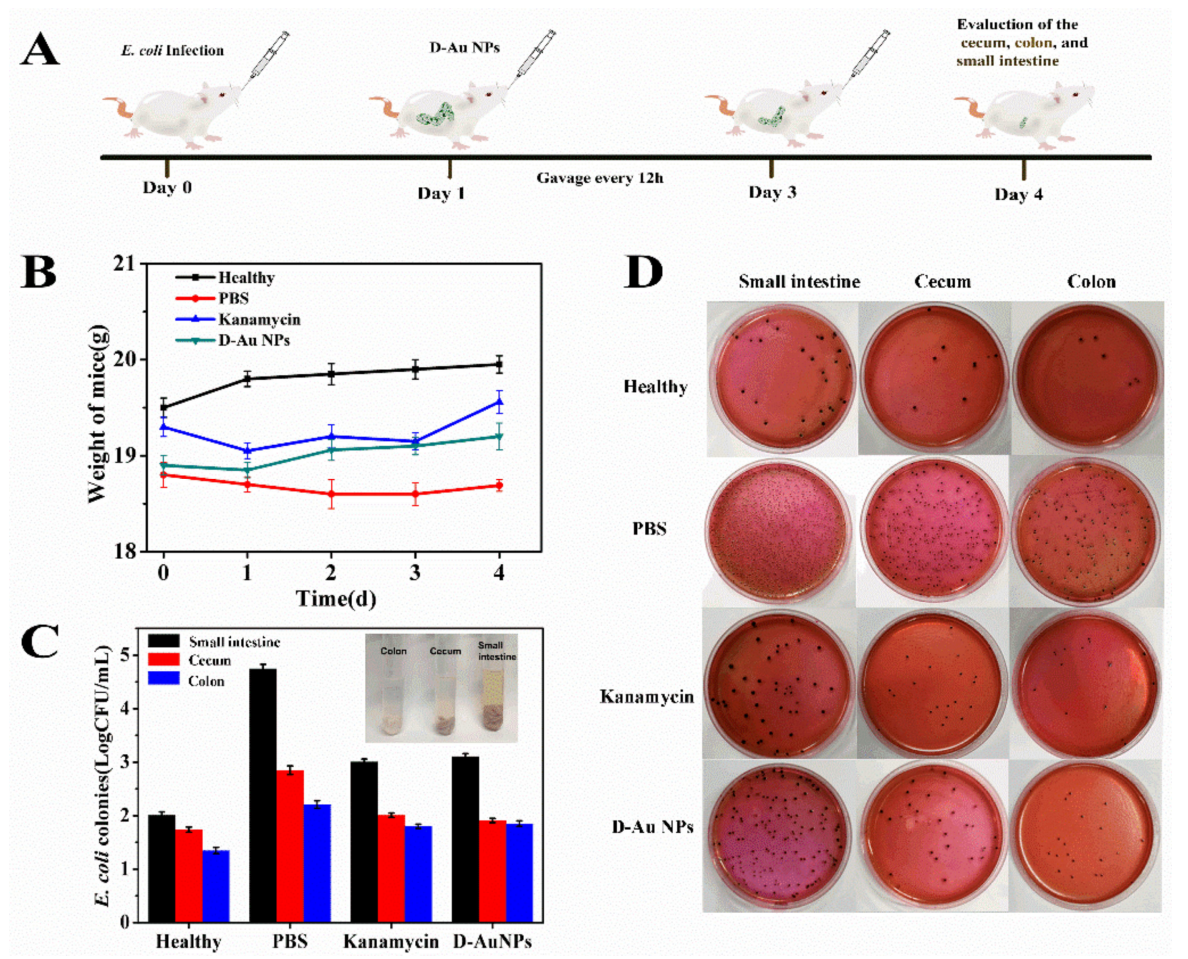

Figure 4. (A) Schematic diagram of the in vivo therapy of E. coli infection with D-Au NPs. Mice were evaluated after 3-days of gavage with PBS, D-Au NPs and kanamycin, respectively. (B) Changes in body weight in mice during the treatment. (C) The survived E. coli in the intestine of the infected mice after different treatments. (Insert: The colon, cecum and small intestine harvested from the infected mice after treatment with D-Au NPs). (Dates are presented as the mean \pm s.d.). (D) Agar plates showing bacterial colonies of the intestine after different treatments.

\subsection{Effects on the Structure of Intestinal Microflora in Mice}

The balance of intestinal microflora is closely related to chronic metabolic diseases, including diabetes, hypoglycemia and gout, which is a matter of great concern in the treatment of infections in the gut. Here, the effect of D-Au NPs on the diversity of microflora in the treatment of E. coli infection in mice was explored [60]. Figure 5A displays the $\alpha$ diversity of intestinal microflora in mice after a 3-day treatment with D-Au NPs, kanamycin (positive control) and PBS (negative control), respectively, containing richness (Chao1 index) and evenness (Shannon and Simpson indexes). The Chao1, Shannon and Simpson indexes showed no obvious difference between the D-Au NPs treated groups and the healthy group. In contrast, the richness of microflora severely decreased after treatment with kanamycin, the Chao1 index decreased from 957.83 to 355.77, and the Shannon index decreased from 4.92 to 4.23 . The results indicated that oral antibiotics for 3 days significantly decreased the diversity of intestinal microflora in mice, whereas D-Au NPs cannot affect the richness and evenness of intestinal microflora [61].

We further investigated the relative abundance of Firmicutes, Bacteroidetes and Proteobacteria in microflora changed after a 3-day administration of D-Au NPs [62]. As shown in Figure 5B, D-Au NPs slightly changed the abundance of Firmicutes, Bacteroidetes and Proteobacteriain microflora in mice compared with the healthy group, whereas kanamycin greatly changed the abundance of bacteria on the phylum level. Kanamycin effectively killed the negative bacteria in the gut so that the proportion of Gram-positive bacteria increased, for example, as in Proteobacteria. At the genus level, D-Au NPs could slightly increase the abundance of Anaerobacterium, and decrease the abundance of Barnesiella, Bacteroides and Lactobacillus. In contrast, kanamycin treatment could greatly increase the relative abundances of Alloprobacillus, Parabacteroides and Vampirovibrioover levels of the healthy group. These results demonstrated that D-Au NPs treatment could not disturb the balance of intestinal microflora during the treatment of infections in the gut. 


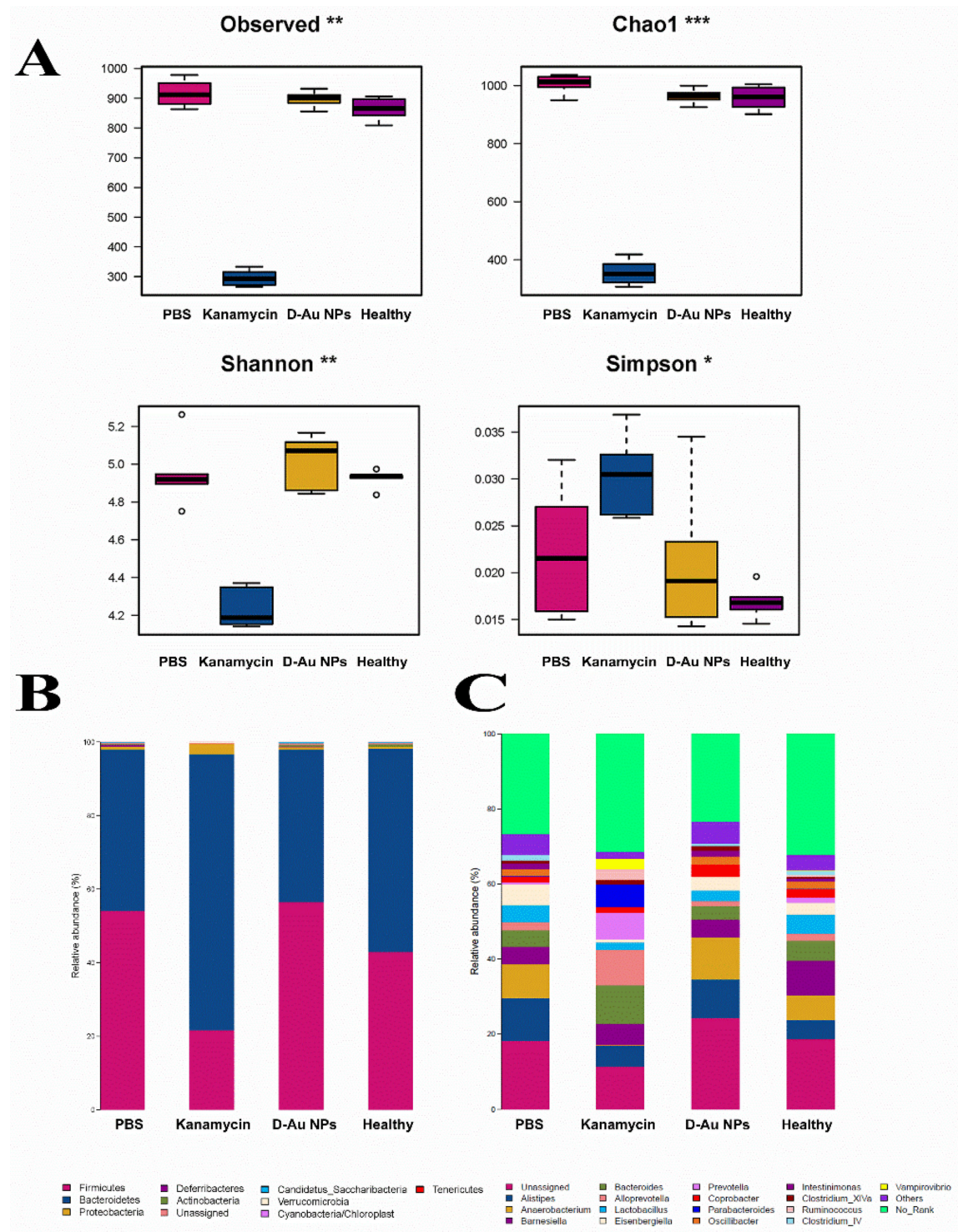

Figure 5. (A) Box plot of Alpha diversity index between PBS, kanamycin, D-Au NPs and healthy groups. (B) Histogram of relative abundance of species at the phylum level. (C) Histogram of relative abundance of species at the genus level. Dates are presented as the mean \pm s.d. *: The mean value of the relative abundance of the species in the group of samples, ${ }^{* * *}>^{* *}>^{*}$.

\section{Conclusions}

In summary, we synthesized an efficient chiral antimicrobial agent by loading D-/Lcysteine on the surface of Au NPs (D-/L-Au NPs). In vitro experiments demonstrated D-Au NPs exhibited the strongest antibacterial activity with E. coli compared with other groups, owing to the synergistic effect of Au NPs and D-cysteine. Mechanism research indicated that the strong antibacterial ability of D-Au NPs can be attributed to damaging cell integrity, which may be caused by a number of reasons. An in-depth investigation of antibacterial mechanisms will be performed in following research. Most importantly, in vivo experiments demonstrated that D-Au NPs displayed a therapeutic effect on the intestinally infected mice comparable with kanamycin, and they could not cause disturbances in intestinal microflora during the treatment of infections in the gut. This research offers a novel approach for the rational design of an effective antibacterial nano agent for the therapy of bacterial infection. 
Author Contributions: Y.X.: Methodology, Formal analysis, Writing-original draft. H.W.: Software, Formal analysis. M.Z.: Formal analysis, Methodology. J.Z.: Formal analysis. W.Y.: Resources, Supervision, Project administration, Funding acquisition, Writing-review and editing. All authors have read and agreed to the published version of the manuscript.

Funding: This research was funded by the National Natural Science Foundation of China, grant number 32072318, 31601569 and China Postdoctoral Science Foundation, grant number 2017T100375, 2016M600420.

Data Availability Statement: Not applicable.

Conflicts of Interest: The authors declare that they have no known competing financial interest or personal relationships that could have appeared to influence the work reported in this paper. There are no conflict to declare.

\section{References}

1. Penha, C.B.; Bonin, E.; da Silva, A.F.; Hioka, N.; Zanqueta, É.B.; Nakamura, T.U.; Filho, B.A.D.A.; Campanerut-Sá, P.A.Z.; Mikcha, J.M.G. Photodynamic Inactivation of Foodborne and Food Spoilage Bacteria by Curcumin. LWT 2017, 76, 198-202. [CrossRef]

2. Wan, M.L.Y.; Forsythe, S.J.; El-Nezami, H. Probiotics Interaction with Foodborne Pathogens: A Potential Alternative to Anti-biotics and Future Challenges. Crit. Rev. Food Sci. Nutr. 2019, 59, 3320-3333. [CrossRef]

3. Liu, Q.; Chen, L.; Laserna, A.K.C.; He, Y.; Feng, X.; Yang, H. Synergistic Action of Electrolyzed Water and Mild Heat for Enhanced Microbial Inactivation of Escherichia coli O157:H7 Revealed by Metabolomics Analysis. Food Control. 2020, 110, 107026. [CrossRef]

4. Hameed, A.S.H.; Louis, G.; Karthikeyan, C.; Thajuddin, N.; Ravi, G. Impact of 1-Arginine and 1-Histidine on the Structural, Optical and Antibacterial Properties of Mg Doped ZnO Nanoparticles Tested Against Extended-spectrum Beta-lactamases (ESBLs) Producing Escherichia coli. Spectrochim. Acta Part A: Mol. Biomol. Spectrosc. 2019, 211, 373-382. [CrossRef]

5. Klebba, P.E.; Newton, S.M.C.; Six, D.A.; Kumar, A.; Yang, T.; Nairn, B.L.; Munger, C.; Chakravorty, S. Iron Acquisition Systems of Gram-Negative Bacterial Pathogens Define Tonb-Dependent Pathways to Novel Antibiotics. Chem. Rev. 2021. [CrossRef]

6. Zheng, W.; Peña, A.; Ilangovan, A.; Clark, J.N.-B.; Frankel, G.; Egelman, E.H.; Costa, T.R.D. Cryoelectron-microscopy Structure of the Enteropathogenic Escherichia coli type III Secretion System EspA filament. Proc. Natl. Acad. Sci. USA 2021, $118,2022826118$. [CrossRef] [PubMed]

7. Godinez, W.J.; Chan, H.; Hossain, I.; Li, C.; Ranjitkar, S.; Rasper, D.; Simmons, R.L.; Zhang, X.; Feng, B.Y. Morphological Decon-volution of Beta-Lactam Polyspecificity in E. coli. ACS Chem. Biol. 2019, 14, 1217-1226. [CrossRef]

8. Levy, N.; Bruneau, J.-M.; Le Rouzic, E.; Bonnard, D.; Le Strat, F.; Caravano, A.; Chevreuil, F.; Barbion, J.; Chasset, S.; Ledoussal, B.; et al. Structural Basis for E. coli Penicillin Binding Protein (PBP) 2 Inhibition, a Platform for Drug Design. J. Med. Chem. 2019, 62, 4742-4754. [CrossRef]

9. Wang, W.; Hao, C.; Sun, M.; Xu, L.; Wu, X.; Xu, C.; Kuang, H. Peptide Mediated Chiral Inorganic Nanomaterials for Combating Gram-Negative Bacteria. Adv. Funct. Mater. 2018, 28, 1805112. [CrossRef]

10. Wang, Y.; Zhang, R.; Li, J.; Wu, Z.; Yin, W.; Schwarz, S.; Tyrrell, J.M.; Zheng, Y.; Wang, S.; Shen, Z.; et al. Comprehensive Resistome Analysis Reveals the Prevalence of NDM and MCR-1 in Chinese Poultry Production. Nat. Microbiol. 2017, 2, 16260. [CrossRef]

11. Card, K.J.; Thomas, M.D.; Jr, J.L.G.; Barrick, J.E.; Lenski, R.E. Genomic Evolution of Antibiotic Resistance is Contingent on Genetic Background Following a Long-term Experiment with Escherichia coli. Proc. Natl. Acad. Sci. USA 2021, 118, 2016886118. [CrossRef]

12. Dik, D.A.; Fisher, J.F.; Mobashery, S. Cell-Wall Recycling of the Gram-Negative Bacteria and the Nexus to Antibiotic Resistance. Chem. Rev. 2018, 118, 5952-5984. [CrossRef] [PubMed]

13. Olesen, S.W.; Lipsitch, M.; Grad, Y.H. The Role of "Spillover" in Antibiotic Resistance. Proc. Natl. Acad. Sci. USA 2020, 117, 29063-29068. [CrossRef]

14. Zhu, G.; Sun, Z.; Hui, P.; Chen, W.; Jiang, X. Composite Film with Antibacterial Gold Nanoparticles and Silk Fibroin for Treating Multidrug-Resistant E. coli-Infected Wounds. ACS Biomater. Sci. Eng. 2021, 7, 1827-1835. [CrossRef]

15. Rolim, W.; Pelegrino, M.T.; Lima, B.D.A.; Ferraz, L.S.; Costa, F.N.; Bernardes, J.S.; Rodigues, T.; Brocchi, M.; Seabra, A.B. Green tea Extract Mediated Biogenic Synthesis of Silver Nanoparticles: Characterization, Cytotoxicity Evaluation and Antibacterial Activity. Appl. Surf. Sci. 2019, 463, 66-74. [CrossRef]

16. Fang, W.-X.; Ma, S.-H.; Dong, H.; Jin, X.-W.; Zou, Y.-C.; Xu, K.-X.; Zhang, L.; Luo, Y.-H. Squarelike AgCl Nanoparticles Grown Using NiCl2(Pyz)2-Based Metal-Organic Framework Nanosheet Templates for Antibacterial Applications. ACS Appl. Nano Mater. 2021. [CrossRef]

17. Mitra, D.; Kang, E.-T.; Neoh, K.G. Polymer-Based Coatings with Integrated Antifouling and Bactericidal Properties for Targeted Biomedical Applications. ACS Appl. Polym. Mater. 2021, 3, 2233-2263. [CrossRef]

18. Das, P.; Maruthapandi, M.; Saravanan, A.; Natan, M.; Jacobi, G.; Banin, E.; Gedanken, A. Carbon Dots for Heavy-Metal Sensing, Ph-Sensitive Cargo Delivery, and Antibacterial Applications. ACS Appl. Nano Mater. 2020, 3, 11777-11790. [CrossRef]

19. Bindhu, M.; Umadevi, M. Antibacterial Activities of Green Synthesized Gold Nanoparticles. Mater. Lett. 2014, 120, 122-125. [CrossRef] 
20. Tang, Y.; Sun, H.; Shang, Y.; Zeng, S.; Qin, Z.; Yin, S.; Li, J.; Liang, S.; Lu, G.; Liu, Z. Spiky Nanohybrids of Titanium Dioxide/Gold Nanoparticles for Enhanced Photocatalytic Degradation and Anti-bacterial Property. J. Colloid Interface Sci. 2019, 535, 516-523. [CrossRef]

21. Kose, O.; Tomatis, M.; Leclerc, L.; Belblidia, N.-B.; Hochepied, J.-F.; Turci, F.; Pourchez, J.; Forest, V. Impact of the Physicochemical Features of TiO2 Nanoparticles on Their In vitro Toxicity. Chem. Res. Toxicol. 2020, 33, 2324-2337. [CrossRef] [PubMed]

22. Mukherjee, M.; Gangopadhyay, K.; Das, R.; Purkayastha, P. Development of Non-Ionic Surfactant and Protein-Coated Ul-trasmall Silver Nanoparticles: Increased Viscoelasticity Enables Potency in Biological Applications. ACS Omega 2020, 5, 8999-9006. [CrossRef]

23. Verma, S.K.; Jha, E.; Panda, P.K.; Thirumurugan, A.; Parashar, S.K.S.; Patro, S.; Suar, M. Mechanistic Insight into Size-Dependent Enhanced Cytotoxicity of Industrial Antibacterial Titanium Oxide Nanoparticles on Colon Cells Because of Reactive Oxygen Species Quenching and Neutral Lipid Alteration. ACS Omega 2018, 3, 1244-1262. [CrossRef]

24. Li, J.; Chen, R.; Zhang, S.; Ma, Z.; Luo, Z.; Gao, G. Chiral Effect at Nano-Bio Interface: A Model of Chiral Gold Nanoparticle on Amylin Fibrillation. Nanomaterials 2019, 9, 412. [CrossRef]

25. Hove, J.B.T.; Schijven, L.M.I.; Wang, J.; Velders, A.H. Size-controlled and Water-soluble Gold Nanoparticles Using UV-induced Ligand Exchange and Phase Transfer. Chem. Commun. 2018, 54, 13355-13358. [CrossRef]

26. Sztandera, K.; Gorzkiewicz, M.; Klajnert-Maculewicz, B. Gold Nanoparticles in Cancer Treatment. Mol. Pharm. 2019, 16, 1-23. [CrossRef]

27. Guo, C.; Zhang, Y.; Li, Y.; Zhang, L.; Jiang, H.; Tao, J.; Zhu, J. Gold Nanoparticle-guarded Large-Pore Mesoporous Silica Nanocomposites for Delivery and Controlled Release of Cytochrome c. J. Colloid Interface Sci. 2021, 589, 34-44. [CrossRef] [PubMed]

28. Wang, K.; Li, Z.; Wang, C.; Zhang, S.; Cui, W.; Xu, Y.; Zhao, J.; Xue, H.; Li, J. Assembled Cationic Dipeptide-Gold Nanoparticle Hybrid Microspheres for Electrochemical Biosensors with Enhanced Sensitivity. J. Colloid Interface Sci. 2019, 557, 628-634. [CrossRef]

29. Wang, L.; Li, S.; Yin, J.; Yang, J.; Li, Q.; Zheng, W.; Liu, S.; Jiang, X. The Density of Surface Coating Can Contribute to Different Antibacterial Activities of Gold Nanoparticles. Nano Lett. 2020, 20, 5036-5042. [CrossRef] [PubMed]

30. MubarakAli, D.; Thajuddin, N.; Jeganathan, K.; Gunasekaran, M. Plant Extract Mediated Synthesis of Silver and Gold Nanoparticles and Its Antibacterial Activity against Clinically Isolated Pathogens. Colloids Surf. B Biointerfaces 2011, 85, 360-365. [CrossRef] [PubMed]

31. Ganguly, S.; Das, P.; Bose, M.; Das, T.K.; Mondal, S.; Das, A.K.; Das, N.C. Sonochemical Green Reduction to Prepare Ag Nanoparticles Decorated Graphene Sheets for Catalytic Performance and Antibacterial Application. Ultrasonics Sonochem. 2017, 39, 577-588. [CrossRef]

32. Zheng, W.; Jia, Y.; Chen, W.; Wang, G.; Guo, X.; Jiang, X. Universal Coating from Electrostatic Self-Assembly to Prevent Multidrug-Resistant Bacterial Colonization on Medical Devices and Solid Surfaces. ACS Appl. Mater. Interfaces 2017, 9, 21181-21189. [CrossRef] [PubMed]

33. Monteil, M.; Moustaoui, H.; Picardi, G.; Aouidat, F.; Djaker, N.; de la Chapelle, M.L.; Lecouvey, M.; Spadavecchia, J. Polyphosphonate Ligands: From Synthesis to Design of Hybrid Pegylated Nanoparticles toward Phototherapy Studies. J. Colloid Interface Sci. 2018, 513, 205-213. [CrossRef] [PubMed]

34. Xing, X.; Ma, W.; Zhao, X.; Wang, J.; Yao, L.; Jiang, X.; Wu, Z. Interaction between Surface Charge-Modified Gold Nanoparticles and Phospholipid Membranes. Langmuir 2018, 34, 12583-12589. [CrossRef]

35. Jana, S.K.; Gucchait, A.; Paul, S.; Saha, T.; Acharya, S.; Hoque, K.M.; Misra, A.K.; Chatterjee, B.K.; Chatterjee, T.; Chakrabarti, P. Virstatin-Conjugated Gold Nanoparticle with Enhanced Antimicrobial Activity against the Vibrio cholerae El Tor Biotype. ACS Appl. Bio Mater. 2021, 4, 3089-3100. [CrossRef]

36. Ferro, I.; Chelysheva, I.; Ignatova, Z. Competition for Amino Acid Flux Among Translation, Growth and Detoxification in Bacteria. RNA Biol. 2017, 15, 1-4. [CrossRef]

37. Loddeke, M.; Schneider, B.; Oguri, T.; Mehta, I.; Xuan, Z.; Reitzer, L. Anaerobic Cysteine Degradation and Potential Metabolic Coordination in Salmonella enterica and Escherichia coli. J. Bacteriol. 2017, 199. [CrossRef]

38. Dong, S.-L.; Xu, Y.; Chen, Y.-Z.; Yan, X.-S.; Li, Z.; Xie, J.-W.; Jiang, Y.-B. Chiral Recognition by Flexible Coordination Polymers of Ag+ with a Cysteine-Based Chiral Thiol Ligand That Bears a Binding Site. Inorg. Chem. 2021, 60, 5413-5418. [CrossRef]

39. Liu, M.; Liu, Y.; Cao, M.-J.; Liu, G.-M.; Chen, Q.; Sun, L.; Chen, H. Antibacterial Activity and Mechanisms of Depolymerized Fucoidans Isolated from Laminaria japonica. Carbohydr. Polym. 2017, 172, 294-305. [CrossRef]

40. Ma, W.; Zhang, D.; Li, G.; Liu, J.; He, G.; Zhang, P.; Yang, L.; Zhu, H.; Xu, N.; Liang, S. Antibacterial Mechanism of Daptomycin Antibiotic Against Staphylococcus aureus Based on a Quantitative Bacterial Proteome Analysis. J. Proteom. 2017, 150, $242-251$. [CrossRef] [PubMed]

41. Wang, H.; Qian, J.; Gu, J.; Yan, W.; Zhang, J. Steric Configuration-enabled Selective Antimicrobial Activity of Chiral Cysteine. Biochem. Biophys. Res. Commun. 2019, 512, 505-510. [CrossRef]

42. Lin, Y.-M.; Song, C.; Rutledge, G.C. Direct Three-Dimensional Visualization of Membrane Fouling by Confocal Laser Scanning Microscopy. ACS Appl. Mater. Interfaces 2019, 11, 17001-17008. [CrossRef] 
43. Ledwaba, S.E.; Costa, D.V.S.; Bolick, D.T.; Giallourou, N.; Medeiros, P.H.Q.S.; Swann, J.R.; Traore, A.N.; Potgieter, N.; Nataro, J.P.; Guerrant, R.L. Enteropathogenic Escherichia coli Infection Induces Diarrhea, Intestinal Damage, Metabolic Alterations, and Increased Intestinal Permeability in a Murine Model. Front. Cell. Infect. Microbiol. 2020, 10, 18. [CrossRef] [PubMed]

44. Yan, W.; Yang, L.; Wang, H.; Zhang, J.; Shen, W. Atomic-engineered Gold@silvergold Alloy Nanoflowers for in vivo Inhibition of Bacteria. Nanoscale 2018, 10, 15661-15668. [CrossRef] [PubMed]

45. Jiang, X.-T.; Peng, X.; Deng, G.-H.; Sheng, H.-F.; Wang, Y.; Zhou, H.-W.; Tam, N.F.-Y. Illumina Sequencing of $16 \mathrm{~S}$ rRNA Tag Revealed Spatial Variations of Bacterial Communities in a Mangrove Wetland. Microb. Ecol. 2013, 66, 96-104. [CrossRef] [PubMed]

46. Wang, Y.; Sheng, H.-F.; He, Y.; Wu, J.-Y.; Jiang, Y.-X.; Tam, N.F.-Y.; Zhou, H.-W. Comparison of the Levels of Bacterial Diversity in Freshwater, Intertidal Wetland, and Marine Sediments by Using Millions of Illumina Tags. Appl. Environ. Microbiol. 2012, 78, 8264-8271. [CrossRef]

47. Jain, A.; Trindade, G.F.; Hicks, J.M.; Potts, J.C.; Rahman, R.; Hague, R.J.M.; Amabilino, D.B.; Perez-Garcia, L.; Rawson, F.J. Mod-ulating the Biological Function of Protein by Tailoring the Adsorption Orientation on Nanoparticles. J. Colloid Interface Sci. 2021, 587, 150-161. [CrossRef]

48. Yang, X.; Roling, L.T.; Vara, M.; Elnabawy, A.O.; Zhao, M. Synthesis and Characterization of Pt-Ag Alloy Nanocages with Enhanced Activity and Durability toward Oxygen Reduction. Nano Letters 2016, 16, 6644. [CrossRef]

49. Zhao, Q.F.; Yang, Y.; Wang, H.L.; Lei, W.; Liu, Y.X.; Wang, S.L. Gold Nanoparticles Modified Hollow Carbon System for Du-al-Responsive Release and Chemo-Photothermal Synergistic Therapy of Tumor. J. Colloid Interface Sci. 2019, 554, $239-249$. [CrossRef]

50. Wei, T.; Tang, Z.; Yu, Q.; Chen, H. Smart Antibacterial Surfaces with Switchable Bacteria-Killing and Bacteria-Releasing Capabilities. ACS Appl. Mater. Interfaces 2017, 9, 37511-37523. [CrossRef] [PubMed]

51. Sardo, C.; Nottelet, B.; Triolo, D.; Giammona, G.; Garric, X.; Lavigne, J.-P.; Cavallaro, G.; Coudane, J. When Functionalization of PLA Surfaces Meets Thiol-Yne Photochemistry: Case Study with Antibacterial Polyaspartamide Derivatives. Biomacromolecules 2014, 15, 4351-4362. [CrossRef] [PubMed]

52. Kolodkin-Gal, I.; Romero, D.; Cao, S.; Clardy, J.; Kolter, R.; Losick, R. D-Amino Acids Trigger Biofilm Disassembly. Science 2010, 328, 627-629. [CrossRef] [PubMed]

53. Hoeflinger, J.L.; Davis, S.R.; Chow, J.; Miller, M. In vitro Impact of Human Milk Oligosaccharides on Enterobacteriaceae Growth. J. Agric. Food Chem. 2015, 63, 3295-3302. [CrossRef]

54. Alavi, M.; Karimi, N.; Valadbeigi, T. Antibacterial, Antibiofilm, Antiquorum Sensing, Antimotility, and Antioxidant Activities of Green Fabricated Ag, Cu, Tio2, Zno, and Fe3o4 Nps Via Protoparmeliopsis Muralis Lichen Aqueous Extract against Mul-ti-DrugResistant Bacteria. ACS Biomater. Sci. Eng. 2019, 5, 4228-4243. [CrossRef]

55. Cui, Y.; Zhao, Y.; Tian, Y.; Zhang, W.; Lü, X.; Jiang, X. The Molecular Mechanism of Action of Bactericidal Gold Nanoparticles on Escherichia coli. Biomaterials 2012, 33, 2327-2333. [CrossRef] [PubMed]

56. Sun, Z.; Zheng, W.; Zhu, G.; Lian, J.; Wang, J.; Hui, P.; He, S.; Chen, W.; Jiang, X. Albumin Broadens the Antibacterial Capabilities of Nonantibiotic Small Molecule-Capped Gold Nanoparticles. ACS Appl. Mater. Interfaces 2019, 11, 45381-45389. [CrossRef] [PubMed]

57. Slocik, J.M.; Dennis, P.B.; Govorov, A.O.; Bedford, N.M.; Ren, Y.; Naik, R.R. Chiral Restructuring of Peptide Enantiomers on Gold Nanomaterials. ACS Biomater. Sci. Eng. 2019, 6, 2612-2620. [CrossRef]

58. Zhang, M.; Ma, Y.; Wang, H.; Wang, B.; Zhou, Y.; Liu, Y.; Shao, M.; Huang, H.; Lu, F.; Kang, Z. Chiral Control of Carbon Dots via Surface Modification for Tuning the Enzymatic Activity of Glucose Oxidase. ACS Appl. Mater. Interfaces 2021, 13, 5877-5886. [CrossRef]

59. Xin, Q.; Liu, Q.; Geng, L.; Fang, Q.; Gong, J.R. Chiral Nanoparticle as a New Efficient Antimicrobial Nanoagent. Adv. Healthc. Mater. 2016, 6, 1601011. [CrossRef]

60. Li, J.; Cha, R.; Zhao, X.; Guo, H.; Luo, H.; Wang, M.; Zhou, F.; Jiang, X. Gold Nanoparticles Cure Bacterial Infection with Benefit to Intestinal Microflora. ACS Nano 2019, 13, 5002-5014. [CrossRef]

61. Seo, K.-H.; Kim, D.-H.; Yokoyama, W.H.; Kim, H. Synbiotic Effect of Whole Grape Seed Flour and Newly Isolated Kefir Lactic Acid Bacteria on Intestinal Microbiota of Diet-Induced Obese Mice. J. Agric. Food Chem. 2020, 68, 13131-13137. [CrossRef] [PubMed]

62. Wei, Y.; Yang, H.; Zhu, C.; Deng, J.; Fan, D. Hypoglycemic Effect of Ginsenoside Rg5 Mediated Partly by Modulating Gut Mi-crobiota Dysbiosis in Diabetic Db/Db Mice. J. Agric. Food Chem. 2020, 68, 5107-5117. [CrossRef] [PubMed] 